\title{
Antioxidant Capacity and Bioaccessibility of Synergic Mango (cv. Ataulfo) Peel Phenolic Compounds in Edible Coatings Applied to Fresh-Cut Papaya
}

\author{
Gustavo Rubén Velderrain-Rodríguez¹, Maribel Ovando-Martínez¹, \\ Mónica Villegas-Ochoa1, Jesús Fernando Ayala-Zavala1, Abraham Wall-Medrano², \\ Emilio Álvarez-Parrilla², Tomás Jesús Madera-Santana1, Humberto Astiazarán-García ${ }^{3}$, \\ Orlando Tortoledo-Ortiz ${ }^{3}$, Gustavo Adolfo González-Aguilar ${ }^{1^{*}}$ \\ ${ }^{1}$ Coordinación en Tecnología de Alimentos de Origen Vegetal, Centro de Investigación en Alimentación y \\ Desarrollo, Hermosillo, México \\ ${ }^{2}$ Instituto de Ciencias Biomédicas, Universidad Autónoma de Ciudad Juárez, Chihuahua, México \\ ${ }^{3}$ Departamento de Nutrición Humana, Coordinación de Nutrición, Centro de Investigación en Alimentación y \\ Desarrollo, Hermosillo, México \\ Email: "gustavo@ciad.mx
}

Received 21 February 2015; accepted 10 March 2015; published 16 March 2015

Copyright (C) 2015 by authors and Scientific Research Publishing Inc.

This work is licensed under the Creative Commons Attribution International License (CC BY).

http://creativecommons.org/licenses/by/4.0/

c) (i) Open Access

\section{Abstract}

Edible coatings (EC) applied to fresh-cut fruits are used to increase their shelf-life and to deliver antioxidant bioactives such as phenolic compounds (PC) that reduce their oxidative damage while enhance their functional value. However, the combination of different PC may have synergetic, additive or antagonic effects on the final antioxidant capacity (AOXC). The aim of this study was to examine the AOXC of binary combinations of selected PC from mango peel and their bioaccessibility from 6\% alginate-based EC applied to fresh-cut papaya, under simulated gastrointestinal conditions. Among equimolar (0.1 mM) combinations, gallic + protocatechuic acids (AB) were synergic in radical scavenging activity (RSA) as assayed by DPPH (90\% RSA) and FRAP $(0.39 \mathrm{mg}$ TE/mL) methods; when assayed in $6 \%$ alginate-based EC, their RSA increased $(117.85 \% \mathrm{RSA}, 0.88 \mathrm{mg}$ $\mathrm{TE} / \mathrm{mL}$ ). The application of EC + AB to papaya cubes and further in vitro digestion decreased their AOXC probably due to interactions between EC and papaya's matrix. Therefore, further studies are needed in order to evaluate the effect of combination of phenolic and EC applied in other fruits matrix on antioxidants bioaccessibility.

\footnotetext{
${ }^{*}$ Corresponding author.
} 


\section{Keywords}

\section{Edible Coating, Phenolic Acids, Antioxidant Capacity, Bioaccessibility}

\section{Introduction}

Nowadays, the search for new technologies for food preservation is very important, particularly to inactivate microorganisms and enzymes that affect the nutritional value of foodstuffs. Some of these technologies have the ability to enhance the shelf-life of foods without affecting their quality and safety [1] [2]. Biofilms or edible coatings (EC) are used to reduce decay, weight loss and browning of fresh-cut fruits, prolonging their shelf-life [3]; when used as carriers to deliver bioactive compounds (e.g. antioxidants (AOX)) they also improve their overall quality and protect them against fungal and bacterial spoilage [4]. EC + AOX also rises the functional value of fresh-cut fruits [4] due to the fact that foods with high antioxidant capacity (AOXC) are suitable for preventing and even treating several non-communicable chronic diseases [5].

Phenolic compounds (PC) are the most abundant AOX in the human diet, and are present in edible vegetables, fruits and their by-products [6]. Tropical fruits such as mango are a good source of antioxidant compounds including phenolic acid and flavonoid compounds. The global production of mangoes exceeds 27 million tons per year [7], being the variety Ataulfo the most produced in Mexico representing 5\% of total mango exportations [8]. This variety stands out among other mango cultivars for its sensorial characteristics and value as functional food due its higher content of Vitamin C, carotenoids and PC [9]-[11]. The use of its pulp to produce juices or minimally processed products, generates vast quantities of peel and seeds $(\sim 32 \%)$ which may have nutraceutical potential [12] [13]. Particularly, mango peels are good sources of ascorbate, fructose, insoluble fiber (lignin and hemicelluloses) and monomeric (e.g. gallic and protocatehuic acids) and polymeric (e.g. $\beta$-PGG) PC with antiobesigenic, anti-inflammatory, anti-carcinogenic and anti-diabetic potential [11].

However, PC present in mango pulp or peel interact with its food matrix, other complex carbohydrates (like those present in GI tract) and with other PC. These interactions can either increase or decrease the AOXC due a synergic or antagonic effect [14] and its potential delivering within the GI tract. Such interactions have repercussions on the functional value of mangoes for human health, since strong interactions significantly limit their bioaccesibility. Hence, the application of novel technologies for controlling an efficient delivery of bioactive compounds might be the next big step toward the functional market consolidation. In a previous work we have reported that the in vitro molecular interaction of four of the most important phenolic acids present in mango pulp (chlorogenic, gallic, protocatechuic and vanillic acids) has a synergic effect on the AOXC [15] [16]. However, there is a lack of reports on the use of these PC as additives in edible coating to preserve fresh-cut fruits and its potential bioaccesibility. The aim of this study was to examine the AOXC of binary combinations of selected PC from mango peel and their bioaccessibility from 6\% alginate-based EC applied to fresh-cut papaya, under simulated gastrointestinal conditions.

\section{Material and Methods}

\subsection{Materials}

Papaya (Carica Papaya L. cv Maradol) and mango (Mangifera indica L. cv. Ataulfo) fruits were purchased at a local marked in Hermosillo, Sonora, Mexico. Alginate, ACS phenolic standards (gallic, ferulic, syringic, protocatechuic and 2-hydroxycinnamic acids), DPPH (2,2-diphenyl-1-picrylhydrazyl), TPTZ (2,4,6-Tris(2-pyridyl)-striazine) and Trolox (6-hydroxy-2,5,7,8-tetramethylchromane-2-carboxylic) were purchased form Sigma Aldrich, Toluca, Mexico. All chemicals were of analytical or HPLC grade.

\subsection{Methods}

\subsubsection{Phenolic Compounds Aqueous Extraction}

Mango peel PC was extracted as described by Wong, Leong [17]. Mango peels were grounded using a domestic blender, and PC were extracted using distilled water. The mixture was refrigerated at $-20^{\circ} \mathrm{C}$ and kept in the dark until further analysis. 


\subsubsection{HPLC-DAD PC Identification}

PC profile was done using high-performance liquid chromatography (HPLC; Varian 920-LC) equipped with a diode array detector (DAD). Prior injection $(10 \mu \mathrm{L}), 2 \mathrm{~mL}$ of the aqueous extract was hydrolyzed by mixing it with $1 \mathrm{~mL}$ of $6 \mathrm{~N} \mathrm{HCl}$ during $3 \mathrm{~h}$ at $80^{\circ} \mathrm{C}$. The hydrolyzate was passed through a filter $(0.22 \mu \mathrm{m})$, transferred to sealed vials and injected into the HPLC system. The UV detector was set at $280 \mathrm{~nm}$. Each PC was identified by comparing its retention time and absorption spectra with those obtained with authentic standards under the same HPLC operating conditions. The mobile phase was composed of $1 \%$ formic acid (A) and acetonitrile (B). Initially, a pre-run with $90 \% \mathrm{~A}$ and $10 \% \mathrm{~B}$ with a flow rate of $1 \mathrm{~mL} / \mathrm{min}$ was conducted. Afterwards, the gradient program was as follows (A:B): a) hold at 90:10 for $1 \mathrm{~min}$; b) 95:5 at $12 \mathrm{~min}$; c) 90:10 at $14 \mathrm{~min}$; d) 80:20 at 20 min and hold for 8 min; e) 74:26 at 30 min and hold for 20 min; f) 50:50 at $60.1 \mathrm{~min}$ and hold for 1.9 min; g) 90:10 at $70 \mathrm{~min}$ and hold for $5 \mathrm{~min}$. The flow rate was $1 \mathrm{~mL} / \mathrm{min}$ for the first $30 \mathrm{~min}$ and $0.75 \mathrm{~mL} / \mathrm{min}$ for the last $45 \mathrm{~min}$.

\subsubsection{Antioxidant Capacity (AOXC)}

The AOXC of individual and combinations of selected mango peel PC (gallic acid, protocatechuic acid, syringic acid, ferulic acid and 2-hydroxycinnamic acid) in methanol was assayed by two radical scavenging capacity (RSC) methods. The DPPH (2,2-diphenyl-1-picrylhydrazyl) assay was performed according to Brand-Williams [18] with some modifications. The DPPH radical solution was prepared by dissolving $2.5 \mathrm{mg}$ of DPPH radical in $100 \mathrm{~mL}$ of methanol. The absorbance of solution was adjusted to $0.7 \pm 0.02$ at $515 \mathrm{~nm}$. Aliquots of $20 \mu \mathrm{L}$ of sample were placed in a microplate and $280 \mu \mathrm{L}$ of DPPH radical solution was added to each sample. Samples were incubated for $30 \mathrm{~min}$ in the dark and the absorbance was measured with a microplate reader (FLUOstar Omega, BMG LABTECH). Results were expressed as the percentage of remaining RSC. The FRAP assay was carried out following the method reported by Benzie and Strain [19]. Twenty $\mu \mathrm{L}$ of sample were placed into each microplate well and mixed with $280 \mu \mathrm{L}$ of FRAP solution. The samples were incubated at room temperature in the dark for $30 \mathrm{~min}$ and the absorbance was measured at $630 \mathrm{~nm}$. The results were reported as $\mathrm{mg}$ of Trolox equivalents per $\mathrm{mL}$ of solution (mg TE/mL) using a standard curve of Trolox. Based on AOXC results, the higher synergic combination was selected and evaluated in the next experiments.

\subsubsection{Preparation of Alginate-Based EC}

Alginate solutions $(6 \% \mathrm{w} / \mathrm{v})$ were prepared adding $0.1 \mathrm{M}$ of the synergic PC combination (gallic acid + protocatechuic acid; combination AB). The AOXC was then assayed as previously described and compared to the corresponding aqueous solution. EC were prepared using the casting method where the alginate solutions with or without the synergic PC combination were placed into plates and dry overnight at $40^{\circ} \mathrm{C}$. The alginate solution was used as a control in both EC and biofilms in further analysis.

\subsubsection{EC on Fresh Cut Papaya}

Papaya was cut into pieces of $1 \mathrm{~cm}^{3}$. The EC were applied to the fresh-cut papaya by immersion and dried by air at room temperature for $5 \mathrm{~min}$. Samples were used for AOXC and in vitro bioaccessibility of PC.

\subsubsection{Bioaccessibility of PC}

To analyze the effect of alginate on the release of PC under simulated gastrointestinal conditions, the bioaccessibility of PC in fresh cut papaya with EC and biofilms was determined according to the methodology of SauraCalixto [20], which mimics the physiological conditions of the digestive tract. Samples (300 mg) with $10 \mathrm{~mL}$ of $\mathrm{HCl}-\mathrm{KCl}$ buffer (pH 5.0) were incubated with a pepsin solution $(300 \mathrm{mg} / \mathrm{mL})$ for $60 \mathrm{~min}$ at $40^{\circ} \mathrm{C}$ in a water bath with constant shaking, simulating gastric conditions. Then $4.5 \mathrm{~mL}$ of phosphate buffer ( $\mathrm{pH} 7.5$ ) were added to the samples and $\mathrm{pH}$ was adjusted to 7.5. Additionally, to simulate intestinal digestion conditions, $1 \mathrm{~mL}$ of pancreatin solution $\left(5 \mathrm{mg} / \mathrm{mL}\right.$ ) was added. Samples were incubated at $37^{\circ} \mathrm{C}$ during $6 \mathrm{~h}$ with constant shaking. Finally, the samples were used for AOXC analysis.

\subsubsection{Statistical Analysis}

All tests were performed in triplicate, one-way ANOVA and the Tukey-Kramer multiple comparison test was used to determine significant differences between groups $(p<0.05)$, using the commercial software JMP Software, Version 7.0. 


\section{Results and Discussions}

\subsection{Mango Peel PC Profile}

Figure 1 shows the phenolic profile of the aqueous extract from mango peel. The numbered peaks in the chromatogram correspond to gallic (1), protocatechuic (2), ferulic (3), syringic (4) and 2-hydroxycinnamic acid (5). These results are similar to those found by Palafox-Carlos, Yahia [16] in mango pulp, where they asserts that the main PC found in mango Ataulfo pulp were phenolics acids, especially gallic and protocatechuic acids. Likewise, Sáyago-Ayerdi, Moreno-Hernández [7] found that Ataulfo peel is rich in hydrolysable tannins, which are polymers of phenolic acids [21]. A research was conducted using standard PC, in order to investigate the synergism or antagonism of these compounds when combined and added to an alginate EC. The information generated can provide new knowledge to understand the behavior of single PC and its contribution to the total AOXC. The individual contribution of these PC has been reported previously by Palafox-Carlos, Yahia [16].

\subsection{AOXC of the Identified PC Standards}

Table 1 shows the AOXC of individual and combined solutions of PC in methanol. Beker, Nissen [14], suggested that synergism is a phenomenon that can be more evident in certain compounds which, when combined, can present a more pronounced effect compared to the sum of their individual activity. In this study, most of the combined solutions presented an antagonic effect when DPPH assay was used, except for the combination of gallic-protocatechuic acid (AB) which had a synergic effect. These results are similar to those reported by Palafox-Carlos [15] [16], who found an increase in the inhibition percentage of the DPPH radical with the combination of gallic-protocatechuic acid compared with the theoretical sum of its individual AOXC. Regarding to FRAP assay, the combinations $\mathrm{AB}$ and protocatechuic-ferulic acid (BD) showed a synergic effect, whilst the rest combinations had mostly an additive effect. These results indicate that the combination $A B$ enhance both, the transference of electron and hydrogen atoms [DPPH is a method for hydrogen atom transference (HAT), and FRAP is a specific method for electron transference (SET)] [22]. Among the binary PC combinations studied, the $\mathrm{AB}$ combination was selected for its application in the $6 \%$ alginate EC.

\subsection{AOXC of PC in Alginate Solution}

Alginate molecules are unbranched polysaccharides consisting of $1 \rightarrow 4$ linked $\beta$-D-mannuronic acid $(\mathrm{M})$ and its C-5 epimer $\alpha$-L-guluronic acid (G) [23]. Falkeborg, Cheong [24] suggested that the antioxidant contribution of alginate molecules is due to hydrogen abstraction from the carbon-bonded hydrogens in glucuronic acid. Hernandez-Marin and Martinez [25], after theoretical studies, have concluded that the antioxidant mechanism of carbohydrates is mainly by HAT from carbon-bonded hydrogens and lees likely to be SET. However, it was observed that the PC (gallic and protocatechuic acids) added into alginate solutions resulted in a slight increase of

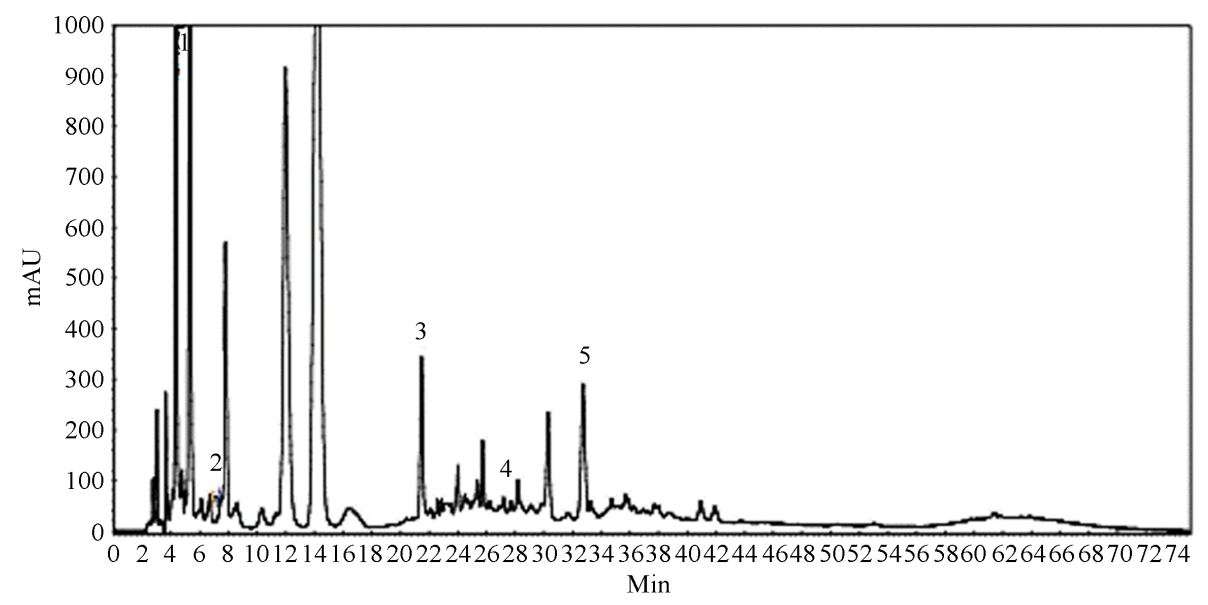

Figure 1. Identified phenolic compounds on mango cv Ataulfo peel aqueous extract by HPLCDAD. (1) Gallic acid, (2) Protocatechuic acid, (3) Syringic acid, (4) Ferulic acid, (5) 2-hydroxycinnamic acid. 
Table 1. Antioxidant capacity of individual and mixtures of phenolic acids representative of those found in mango peel. Gallic acid (A), protocatechuic acid (B), siringic acid (C), ferulic acid (D), 2-hydroxycinamic acid (E).

\begin{tabular}{|c|c|c|c|c|c|c|}
\hline \multirow{2}{*}{$\begin{array}{c}\text { Individual } \\
\text { (0.1 mM) }\end{array}$} & \multicolumn{3}{|c|}{ DPPH } & \multicolumn{3}{|c|}{ FRAP } \\
\hline & \% RSA Real & $\begin{array}{c}\text { \% RSA } \\
\text { Theoretical (Sum) }\end{array}$ & $\begin{array}{c}\text { Type of } \\
\text { Interaction }\end{array}$ & mgTE/mL & $\begin{array}{c}\text { mgTE/mL } \\
\text { Theoretical (Sum) }\end{array}$ & $\begin{array}{c}\text { Type of } \\
\text { Interaction }\end{array}$ \\
\hline A & 49.26a & & & $0.14 \mathrm{a}$ & & \\
\hline B & $27.26 b$ & & & $0.07 \mathrm{~b}$ & & \\
\hline $\mathrm{C}$ & 28.90b & & & $0.09 b$ & & \\
\hline $\mathrm{D}$ & 19.61c & & & $0.07 \mathrm{~b}$ & & \\
\hline $\mathrm{E}$ & 9.819d & & & $0.01 \mathrm{c}$ & & \\
\hline Combination & \% RSA Real & $\begin{array}{c}\text { \% RSA } \\
\text { Theoretical (Sum) }\end{array}$ & $\begin{array}{c}\text { Type of } \\
\text { Interaction }\end{array}$ & mgTE/mL & $\begin{array}{c}\text { mgTE/mL } \\
\text { Theoretical (Sum) }\end{array}$ & $\begin{array}{c}\text { Type of } \\
\text { Interaction }\end{array}$ \\
\hline $\mathrm{AB}$ & $90.04 a$ & $76.53 b$ & Synergic & $0.36 a$ & $0.22 b$ & Synergic \\
\hline $\mathrm{AC}$ & $61.47 \mathrm{~b}$ & 78.16a & Antagonist & $0.24 \mathrm{a}$ & $0.24 \mathrm{a}$ & Additive \\
\hline $\mathrm{AD}$ & $52.56 b$ & $68.87 a$ & Antagonist & $0.23 a$ & $0.22 \mathrm{a}$ & Additive \\
\hline $\mathrm{AE}$ & 48.65b & 59.08a & Antagonist & $0.10 \mathrm{~b}$ & $0.16 a$ & Antagonist \\
\hline $\mathrm{BC}$ & $45.76 b$ & 56.17a & Antagonist & $0.17 \mathrm{a}$ & $0.17 \mathrm{a}$ & Additive \\
\hline $\mathrm{BD}$ & $35.47 b$ & 46.87a & Antagonist & $0.18 \mathrm{a}$ & $0.15 b$ & Synergic \\
\hline $\mathrm{BE}$ & 25.99b & $37.08 \mathrm{a}$ & Antagonist & $0.11 \mathrm{a}$ & $0.09 \mathrm{a}$ & Additive \\
\hline $\mathrm{CD}$ & 31.34b & 48.51a & Antagonist & $0.18 \mathrm{a}$ & $0.17 \mathrm{a}$ & Additive \\
\hline $\mathrm{CE}$ & 32.31b & $38.72 \mathrm{a}$ & Antagonist & $0.11 \mathrm{a}$ & $0.11 \mathrm{a}$ & Additive \\
\hline
\end{tabular}

Different letters in each column of individual standards indicates significant differences $(p \leq 0.05)$ between standards for each method; whereas in combination, different letters indicates differences $(p \leq 0.05)$ between real and theoretical values for each method.

the AOXC of the protocatechuic acid measured by the DPPH assay (Figure 2(B)), whilst the AOXC by FRAP assay showed 2 fold increase (Figure 2(D)). These results, according to Peshev and Vergauwen [26], suggest that the antioxidant mechanism followed by the combination of alginate, gallic and protocathechuic acid are not entirely by hydrogen donation. As Peshev, Vergauwen [26] described, if double bonds are present in the antioxidant molecules they follow the radical addition mechanism, which is not considered as a possible mechanism for carbohydrates, but it is for PC [24]. It means that the capacity of the synergic combination to donate electrons is not restricted, but enhanced by the presence of alginate, following diverse possible antioxidant mechanisms.

\subsection{AOXC and Bioaccessibility of PC Added in Alginate Edible Films}

Figure 3 shows the results of the AOXC by FRAP method in the EC with 6\% alginate and PC. These results indicates that there is an antioxidant synergism related with the transference of electrons, which can be determined by the FRAP assay in the simulated physiological conditions. Nonetheless, these values are lower than those determined in the pure standards in methanol and standards with alginate under the same method (Figure 2). Such differences in the AOXC could be due to the low stability of the PC at basic pH. These results agreed with those reported by Friedman and Jürgens [27], that states that simple PC with low molecular weight such as phenolic acids are susceptible to oxidation under high pH conditions. Under this condition, PC are oxidized and a chemical structure change takes place, being irreversible and directly affecting the AOXC in both transference of hydrogens (HAT) and electrons (SET) mechanisms.

On the other hand, from the nutritional point of view, some carbohydrates polymers like alginate have gelation properties, which can affect the bioaccessibility of bioactive compounds being trapped within the crosslinked chains of the polymers. Those cross-linked chains are the result of the carbohydrates gelification proper- 


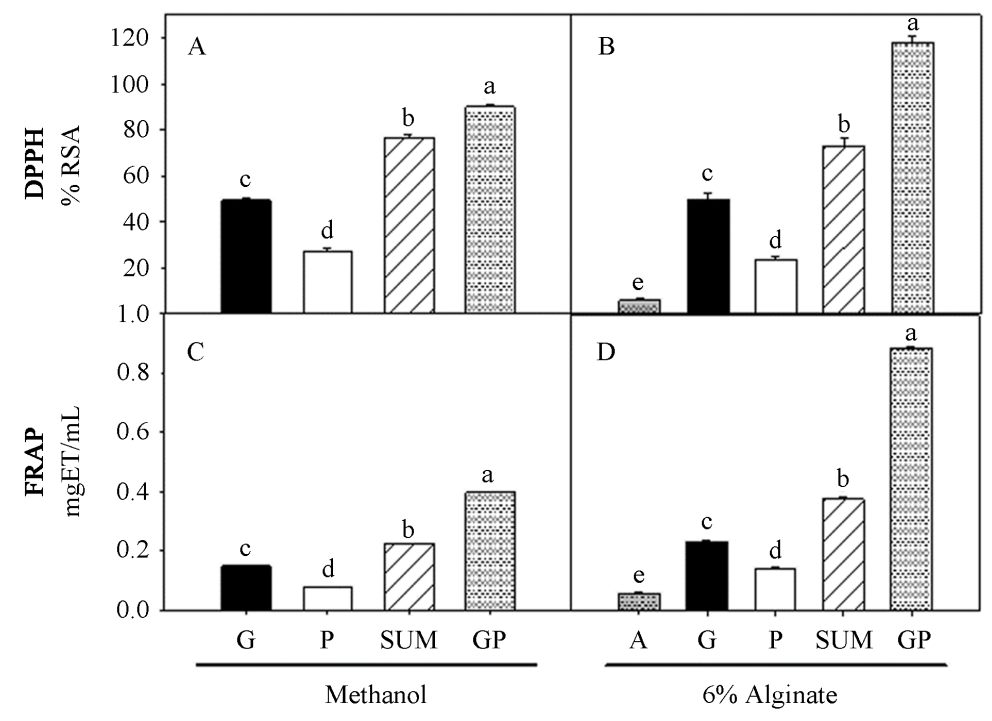

Figure 2. Comparison of antioxidant activity by FRAP and DPPH methods of gallic and protocatechuic acids standards in methanol and $6 \%$ alginate (A) solutions. Each bar represents the standard solutions with gallic acid (G), protocatechuic acid (P), gallic and protocatechuic acid theoretical sum (SUM) and the real values of gallic-protocatechuic combination (GP). Values are the mean \pm Std error $(n=3)$. Different letters indicate statistical differences $(p \leq 0.05)$.

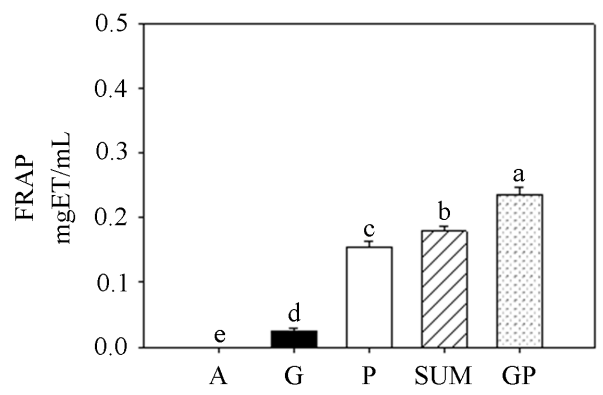

Figure 3. Antioxidant activity by FRAP assay of $6 \%$ Alginate (A) edible films added with phenolic compounds gallic-protocatechuic synergic combination. Each bar represents the edible films with gallic acid (G), protocatechuic acid (P), gallic and protocatechuic acid theoretical sum (SUM) and the real values of gallic-protocatechuic combination (GP). Values are the mean \pm Std error (n $=3)$. Different letters indicate statistical differences $(p \leq 0.05)$.

ties, i.e. alginate undergoes the sol-to-gel transition upon lowering $\mathrm{pH}$ even in the absence of cations [28]. Therefore, this indicates that PC added to the EC have low bioaccessibility due to the changes mentioned previously, affecting the rheological properties of alginate. This suggests that during the digestion in the upper gastrointestinal tract, the acid conditions enhance the interaction of alginate with PC, decreasing their bioaccessibility in the lower gastrointestinal tract.

\subsection{AOXC and Bioaccessibility of PC Added to EC Applied in Papaya}

The study of the AOXC in FRAP assay of PC released from the in vitro digestion of fresh-cut papaya with 6\% alginate EC is presented in Figure 4. These results indicated that the AOXC in FRAP assay decreased, compared to theoretical values, which suggests a lower electron transfer. Nonetheless, when the EC mixed with gallic acid was applied to the papaya fruit a strong antagonism was observed, resulting in lower FRAP values than those found in papaya without EC. This could be due to the chemical-enzymatic conditions involved in the in vitro digestion [28] [29]. During the study of the bioaccessibility of PC with the in vitro digestion model dif- 


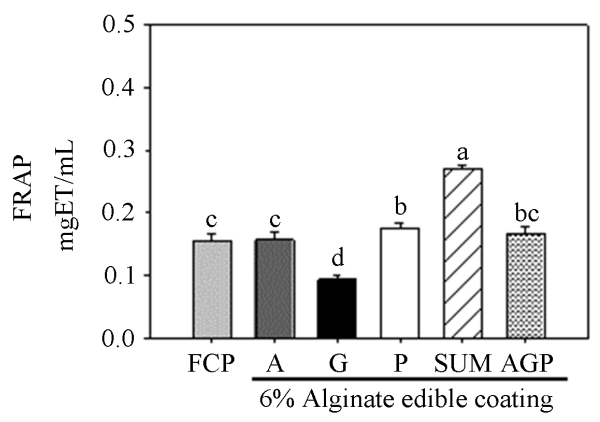

Figure 4. Comparison of antioxidant activity by FRAP assay of fresh cut papaya (FCP) with different $6 \%$ Alginate (A) edible coatings. Each bar represents the edible coatings with gallic acid $(\mathrm{G})$, protocatechuic acid $(\mathrm{P})$, gallic and protocatechuic acid theoretical sum (SUM) and the real values of gallic-protocatechuic combination (GP). Values are the mean \pm Std error $(n=3)$. Different letters indicate statistical differences $(p \leq 0.05)$.

ferent digestion phases were emulated. In the gastric phase the environment was acid ( $\mathrm{pH} 1.5)$ while in the intestinal phase the acid environment decreased ( $\mathrm{pH}$ 7.5). The AOXC measurement was performed at the intestinal phase, which has a less protonated environment, as compared to that of standards in methanol solution or in alginate, where the $\mathrm{pH}$ was between 6 - 7 .

On the other hand, papaya is a fruit rich in soluble dietary fiber, especially pectin [30]. It has been reported that pectin produces an antioxidant antagonism in AOXC methods due to an interaction between pectin and gallic acid forming hydrogen bonds [31]. In the same way, the alginate chains contain electronegative D-mannuric and D-guluronic groups, so, the hydrogen atoms present in gallic acid could interact with both the pectin from papaya and the alginate chains in the EC [32]. As pectin and alginate have similar gelation properties, both molecules are able to form gel at low $\mathrm{pH}$ in presence of hydrophilic molecules. In this case, as gallic and protocatechuic acids are hydrophilic molecules, their presence may induce hydrophobic interactions or hydrogen bonds between pectin and alginate at low $\mathrm{pH}$. These hydrogen bonds reduce the ability of gallic acid molecules to donate either electrons or hydrogen atoms, either due to their inaccessible position within the pectin/alginate branches or to the changes in the molecules reactivity. This can help us to explain the antagonistic effect found in the AOXC of the EC with gallic acid. However, this interaction between PC and alginate was not observed in the absence of papaya fruit, which supports the idea that antagonistic effect is given due to the cross-linked chains formed between papaya's pectin and alginate molecules under acid conditions. In the same way, it suggest that the bioaccessibility of the PC added in the alginate EC is decreasing by the interactions of them with the alginate and dietary fiber present in papaya fruit.

\section{Conclusion}

According to these results, we concluded that alginate EC kept the antioxidant properties, maintaining the synergic effect reported for gallic-protocatechuic acids combination. However, the presence of dietary fiber, such as pectin in the food matrix of the papaya fruit, appears to be a limiting factor in the synergic effect of PC that negatively affect its bioaccessibility. Further studies using UV-VIS, fluorescence, ITC, and FT-IR techniques can be performed to elucidate the possible interactions among alginate coatings, edible films and gallic acid.

\section{Acknowledgements}

We thanks to CIAD and CONACYT-Mexico for their financial support. This work is part of the project "Nutrigenómica e interacciones moleculares de fenoles y fibra dietaria del mango 'Ataulfo' (Mangifera indica, L.) en un sistema murino" Project 179574CB2012-01 and Red AlFaNutra.

\section{References}

[1] Kester, J. and Fennema, O. (1986) Edible Films and Coatings: A Review. Food Technology, 40, 47-59.

[2] Alikhani, M. (2014) Enhancing Safety and Shelf Life of Fresh-Cut Mango by Application of Edible Coatings and Mi- 
croencapsulation Technique. Food Science \& Nutrition, 2, 210-217.

[3] Rojas-Graü, M.A., Soliva-Fortuny, R. and Martín-Belloso, O. (2009) Edible Coatings to Incorporate Active Ingredients to Fresh-Cut Fruits: A Review. Trends in Food Science \& Technology, 20, 438-447. http://dx.doi.org/10.1016/j.tifs.2009.05.002

[4] Ponce, A.G., et al. (2008) Antimicrobial and Antioxidant Activities of Edible Coatings Enriched with Natural Plant Extracts: In Vitro and in Vivo Studies. Postharvest Biology and Technology, 49, 294-300. http://dx.doi.org/10.1016/j.postharvbio.2008.02.013

[5] Valko, M., et al. (2007) Free Radicals and Antioxidants in Normal Physiological Functions and Human Disease. The International Journal of Biochemistry \& Cell Biology, 39, 44-84. http://dx.doi.org/10.1016/j.biocel.2006.07.001

[6] Balasundram, N., Sundram, K. and Samman, S. (2006) Phenolic Compounds in Plants and Agri-Industrial By-Products: Antioxidant Activity, Occurrence, and Potential Uses. Food Chemistry, 99, 191-203. http://dx.doi.org/10.1016/j.foodchem.2005.07.042

[7] Sáyago-Ayerdi, S.G., et al. (2013) Mexican “Ataulfo” Mango (Mangifera indica L.) as a Source of Hydrolyzable Tannins. Analysis by MALDI-TOF/TOF MS. Food Research International, 51, 188-194. http://dx.doi.org/10.1016/j.foodres.2012.11.034

[8] Villa-Corrales, L., et al. (2010) Numerical and Experimental Analysis of Heat and Moisture Transfer during Drying of Ataulfo Mango. Journal of Food Engineering, 98, 198-206. http://dx.doi.org/10.1016/j.jfoodeng.2009.12.026

[9] Manthey, J.A. and Perkins-Veazie, P. (2009) Influences of Harvest Date and Location on the Levels of $\beta$-Carotene, Ascorbic Acid, Total Phenols, the in Vitro Antioxidant Capacity, and Phenolic Profiles of Five Commercial Varieties of Mango (Mangifera indica L.). Journal of Agricultural and Food Chemistry, 57, 10825-10830. http://dx.doi.org/10.1021/jf902606h

[10] García-Solís, P., Yahia, E.M. and Aceves, C. (2008) Study of the Effect of “Ataulfo” Mango (Mangifera indica L.) Intake on Mammary Carcinogenesis and Antioxidant Capacity in Plasma of N-Methyl-N-Nitrosourea (MNU)-Treated Rats. Food Chemistry, 111, 309-315. http://dx.doi.org/10.1016/j.foodchem.2008.03.060

[11] Wall-Medrano, A., Olivas-Aguirre, F.J., Velderrain-Rodriguez, G.R., González-Aguilar, G.A., De la Rosa, L.A., LópezDíaz, J.A. and Álvarez-Parrilla, E. (2015) El mango: Aspectos agroindustriales, valor nutricional/funcional y efectos en la salud. Nutricion Hospitalaria, 31, 67-75.

[12] Schieber, A., Ullrich, W. and Carle, R. (2000) Characterization of Polyphenols in Mango Puree Concentrate by HPLC with Diode Array and Mass Spectrometric Detection. Innovative Food Science \& Emerging Technologies, 1, 161-166. http://dx.doi.org/10.1016/S1466-8564(00)00015-1

[13] Ayala-Zavala, J., Rosas-Domínguez, C., Vega-Vega, V. and González-Aguilar, G.A. (2010) Antioxidant Enrichment and Antimicrobial Protection of Fresh-Cut Fruits Using Their Own Byproducts: Looking for Integral Exploitation. Journal of Food Science, 75, R175-R181. http://dx.doi.org/10.1111/j.1750-3841.2010.01792.x

[14] Becker, E., Nissen, L. and Skibsted, L. (2004) Antioxidant Evaluation Protocols: Food Quality or Health Effects. European Food Research and Technology, 219, 561-571. http://dx.doi.org/10.1007/s00217-004-1012-4

[15] Palafox-Carlos, H., Gil-Chávez, J., Sotelo-Mundo, R.R., Namiesnik, J., Gorinstein, S. and González-Aguilar, G.A. (2012) Antioxidant Interactions between Major Phenolic Compounds Found in “Ataulfo” Mango Pulp: Chlorogenic, Gallic, Protocatechuic and Vanillic Acids. Molecules, 17, 12657-12664. http://dx.doi.org/10.3390/molecules171112657

[16] Palafox-Carlos, H., Yahia, E. and González-Aguilar, G. (2012) Identification and Quantification of Major Phenolic Compounds from Mango (Mangifera indica, cv. Ataulfo) Fruit by HPLC-DAD-MS/MS-ESI and Their Individual Contribution to the Antioxidant Activity during Ripening. Food Chemistry, 135, 105-111. http://dx.doi.org/10.1016/j.foodchem.2012.04.103

[17] Wong, S.P., Leong, L.P. and William Koh, J.H. (2006) Antioxidant Activities of Aqueous Extracts of Selected Plants. Food Chemistry, 99, 775-783. http://dx.doi.org/10.1016/j.foodchem.2005.07.058

[18] Brand-Williams, W., Cuvelier, M. and Berset, C. (1995) Use of a Free Radical Method to Evaluate Antioxidant Activity. LWT-Food Science and Technology, 28, 25-30. http://dx.doi.org/10.1016/S0023-6438(95)80008-5

[19] Benzie, I.F. and Strain, J. (1996) The Ferric Reducing Ability of Plasma (FRAP) as a Measure of “Antioxidant Power”: The FRAP Assay. Analytical Biochemistry, 239, 70-76. http://dx.doi.org/10.1006/abio.1996.0292

[20] Saura-Calixto, F., García-Alonso, A., Goñi, I. and Bravo, L. (2000) In Vitro Determination of the Indigestible Fraction in Foods: An Alternative to Dietary Fiber Analysis. Journal of Agricultural and Food Chemistry, 48, 3342-3347. http://dx.doi.org/10.1021/jf0000373

[21] Okuda, T., Yoshida, T. and Hatano, T. (1995) Hydrolyzable Tannins and Related Polyphenols. In: Fortschritte der Chemie organischer Naturstoffe/Progress in the Chemistry of Organic Natural Products, Springer, Berlin, 1-117.

[22] Rojano, B., Saez, J., Schinella, G., Quijano, J., Vélez, E., Gil, A. and Notario, R. (2008) Experimental and Theoretical 
Determination of the Antioxidant Properties of Isoespintanol (2-Isopropyl-3,6-Dimethoxy-5-Methylphenol). Journal of Molecular Structure, 877, 1-6. http://dx.doi.org/10.1016/j.molstruc.2007.07.010

[23] Pawar, S.N. and Edgar, K.J. (2012) Alginate Derivatization: A Review of Chemistry, Properties and Applications. Biomaterials, 33, 3279-3305. http://dx.doi.org/10.1016/j.biomaterials.2012.01.007

[24] Falkeborg, M., Cheong, L.Z., Gianfico, C., Magdalena Sztukiel, K., Kristensen, K., Glasius, M., et al. (2014) Alginate Oligosaccharides: Enzymatic Preparation and Antioxidant Property Evaluation. Food Chemistry, 164, 185-194. http://dx.doi.org/10.1016/j.foodchem.2014.05.053

[25] Hernandez-Marin, E. and Martínez, A. (2012) Carbohydrates and Their Free Radical Scavenging Capability: A Theoretical Study. The Journal of Physical Chemistry B, 116, 9668-9675. http://dx.doi.org/10.1021/jp304814r

[26] Peshev, D., Vergauwen, R., Moglia, A., Hideg, É. and Van den Ende, W. (2013) Towards Understanding Vacuolar Antioxidant Mechanisms: A Role for Fructans? Journal of Experimental Botany, 64, 1025-1038. http://dx.doi.org/10.1093/jxb/ers377

[27] Friedman, M. and Jürgens, H.S. (2000) Effect of pH on the Stability of Plant Phenolic Compounds. Journal of Agricultural and Food Chemistry, 48, 2101-2110. http://dx.doi.org/10.1021/jf990489j

[28] Saura-Calixto, F., Serrano, J. and Goñi, I. (2007) Intake and Bioaccessibility of Total Polyphenols in a Whole Diet. Food Chemistry, 101, 492-501. http://dx.doi.org/10.1016/j.foodchem.2006.02.006

[29] Palafox-Carlos, H., Ayala-Zavala, J.F. and González-Aguilar, G.A. (2011) The Role of Dietary Fiber in the Bioaccessibility and Bioavailability of Fruit and Vegetable Antioxidants. Journal of Food Science, 76, R6-R15. http://dx.doi.org/10.1111/j.1750-3841.2010.01957.x

[30] Manrique, G.D. and Lajolo, F.M. (2002) FT-IR Spectroscopy as a Tool for Measuring Degree of Methyl Esterification in Pectins Isolated from Ripening Papaya Fruit. Postharvest Biology and Technology, 25, 99-107. http://dx.doi.org/10.1016/S0925-5214(01)00160-0

[31] Martínez-de-Santiago, M. (2014) Interacciones entre pectnia y ácidos fenólicos presentes en pulpa de mango (Mangifera indica L.) cv. "Ataulfo” y su efecto en la capacidad antioxidante. Departamento de Ingeniería Agroindustrial, Universidad Autónoma Chapingo, Chapingo.

[32] Fundueanu, G., Nastruzzi, C., Carpov, A., Desbrieres, J. and Rinaudo, M. (1999) Physico-Chemical Characterization of CaAlginate Microparticles Produced with Different Methods. Biomaterials, 20, 1427-1435. http://dx.doi.org/10.1016/S0142-9612(99)00050-2 